\title{
Genetic diversity, functional properties and expression analysis of NnSBE genes involved in starch synthesis of lotus (Nelumbo nucifera Gaertn.)
}

\author{
Fenglin Zhu ${ }^{1,2,3}$, Han Sun ${ }^{1,2,3}$, Ying Diao ${ }^{1,3}$, Xingwen Zheng ${ }^{1,2,3,4}$, Keqiang Xie ${ }^{4}$, Zhongli Hu ${ }^{\text {Corresp. } 1,2,3}$ \\ ${ }^{1}$ College of Life Sciences, Wuhan University, Wuhan, China \\ 2 State Key Laboratory of Hybrid Rice, Wuhan, China \\ 3 Hubei Lotus Engineering Center, Wuhan, China \\ 4 Guangchang Bailian Institute of Jiangxi Province, Guangchang, China \\ Corresponding Author: Zhongli Hu \\ Email address: huzhongli@whu.edu.cn
}

Background Starch branching enzyme (SBE) is one of the key enzymes in starch biosynthetic metabolism, determining amylopectin structure.

Methods Full length coding sequences (CDS) of SBE genes were cloned using reverse transcription PCR (RT-PCR) technology, and neighbor-joining (NJ) tree was used for phylogenetic analysis. Single nucleotide polymorphisms (SNPs) were determined to assess the genetic polymorphisms and variation indexes between individuals and clusters. Quantitative real time PCR (qRT-PCR) was performed to analyze the spatial and temporal expression of NnSBE genes. The effect of NnSBE genes on amylopectin's fine structures was explored using affinity and the enzyme activity analysis of two isoforms in amylopectin and amylose.

Results In this study, two SBE family genes, NnSBEI and NnSBEIII, were identified in lotus (Nelumbo nucifera Gaertn.). Phylogenetic analysis sorted NnSBEI into SBE family B and NnSBEIII into SBE family A. UPGMA phylogenetic tree divided 45 individuals of lotus into three classes. The homozygous haplotype (A G G A G) of NnSBEIII was observed in seed lotus. During the seed embryo development stage, NnSBEIII reached the peak in the middle of the development stage, while NnSBEI increased in the mid-late developmental stage. The different affinity activity of the two isozymes binding amylopectin and amylose assay indicated NnSBEI has higher activity and wider affinity.

Discussion Genetic diversity showed that NnSBE genes received artificial selection during the process of cultivation and domestication in lotus seeds. Furthermore, the expression pattern and affinity activity analysis indicated that NnSBE genes were related to the chain length of amylopectin. 
1 Genetic diversity, functional properties and expression analysis of $\mathrm{NnSBE}$ genes involved

2 in starch synthesis of lotus (Nelumbo nucifera Gaertn.)

3 Fenglin Zhu 1, 2, 3, Han Sun 1,2,3, Ying Diao 1,3, Xingwen Zheng 1,2,3,4, Keqiang Xie ${ }^{4}$, Zhongli

$4 \quad \mathrm{Hu}$ Corresp. 1,2,3

51 College of Life Sciences, Wuhan University, Wuhan, China

62 State Key Laboratory of Hybrid Rice, Wuhan, China

73 Hubei Lotus Engineering Center, Wuhan, China

84 Guangchang Bailian Institute of Jiangxi Province, Guangchang, China

9 *Correspondence: Zhongli Hu. Fax: +86-27-68753606 E-mail huzhongli@whu.edu.cn

\section{Abstract}

Background Starch branching enzyme (SBE) is one of the key enzymes in starch biosynthetic metabolism, determining amylopectin structure.

Methods Full length coding sequences (CDS) of $S B E$ genes were cloned using reverse transcription PCR (RT-PCR) technology, and neighbor-joining (NJ) tree was used for phylogenetic analysis. Single nucleotide polymorphisms (SNPs) were determined to assess the genetic polymorphisms and variation indexes between individuals and clusters. Quantitative real time PCR (qRT-PCR) was performed to analyze the spatial and temporal expression of $N n S B E$ genes. The effect of $N n S B E$ genes on amylopectin's fine structures was explored using affinity and the enzyme activity analysis of two isoforms in amylopectin and amylose.

Results In this study, two SBE family genes, NnSBEI and NnSBEIII, were identified in lotus

(Nelumbo nucifera Gaertn.). Phylogenetic analysis sorted NnSBEI into SBE family B and 
NnSBEIII into SBE family A. UPGMA phylogenetic tree divided 45 individuals of lotus into three classes. The homozygous haplotype (A G G A G) of NnSBEIII was observed in seed lotus. During the seed embryo development stage, NnSBEIII reached the peak in the middle of the development stage, while $N n S B E I$ increased in the mid-late developmental stage. The different affinity activity of the two isozymes binding amylopectin and amylose assay indicated NnSBEI has higher activity and wider affinity.

Discussion Genetic diversity showed that $N n S B E$ genes received artificial selection during the process of cultivation and domestication in lotus seeds. Furthermore, the expression pattern and affinity activity analysis indicated that $N n S B E$ genes were related to the chain length of amylopectin.

\section{Introduction}

Lotus (Nelumbo nucifera Gaertn) is an ancient perennial aquatic plant and important crop in Asia. Archaeological research has estimated that the history of lotus is more than 7,000 years old, and it has been cultivated for more than 2000 years (Guo 2009; Shen-Miller 2002). In general, lotus are grouped into three clusters corresponding with the three different important organs, namely ornament lotus, seed lotus and rhizome lotus, respectively (Guo 2009; Wu et al. 2007). As a type of aquatic plant with high photosynthetic efficiency and high carbon conversion, lotus has high starch content. Because of their high amount of starch, the edible rhizomes and seeds play a key role in a daily diet and cultural activities (Chen et al. 2007). Studies have shown that fresh rhizomes, on average, are comprised of $10-20 \%$ starch in their total fresh weight, while the amount is $40-60 \%$ in mature seeds (Shen-Miller et al. 1995). 
Starch is an important polysaccharide and the major form of carbohydrate storage in plants

44 (Slattery, Kavakli, Okita 2000). It is a necessary part of the human diet in terms of nutrition and

calories. Starch is comprised of two glucan polymers, amylose and amylopectin, which have different characteristics because of their starch molecular structure. Amylose and amylopectin synthesis are regulated by the coordinated action of a series of enzymes. AGPase produces substrate that plays a role in the synthesis of amylose and amylopectin. Amylose synthesis is mainly controlled by granule-bound starch synthase (GBSS), while amylopectin is generated by the successive work of starch synthase (SS), starch branching enzyme (SBE), and debranching enzyme (DBE) (Fujita et al. 2008; Jeon et al. 2010; Subasinghe et al. 2014; Tetlow Ian, Emes

Michael 2014).

Starch-branching enzymes, formerly known as Q-enzymes, have dual catalytic functions and determine the structure of amylopectin. SBE cleaves the internal a-1,4 linkage from polyglucans and then transfers the reducing ends to C-6 hydroxyls to generate a-1,6-branch linkage in the liner chain (Martin, Smith 1995). Their catalytic function not only catalyzes the formation of a new branch, but they also add new nonreducing ends in the starch molecule. Thus, SBE determines the branching pattern in amylopectin, which is believed to affect the fine structure of plants and influence the amount of starch (Satoh et al. 2003).

SBEs have been researched in various plants. In particular, two cDNA coding PSSBEs were identified from the embryo of Pisum sativum by Burton et al (Burton Rachel et al. 1995). Later, two or three SBE members were identified in various plants and were classified into SBE A and SBE B based on phylogenetic analysis. SBE A and SBE B play different roles in the influence of 
64

65

66

67

68

69

amylopectin synthesis. In the process of starch synthesis, the SBE A family tends to amylopectin, while SBE B family show higher affinity for amylose. SBE A prefers amylose as a substrate and predominantly transfers relatively longer chains (>14DP), while SBE B tends to amylopectin and transfers shorter chains (<14DP) (Guan et al. 1997). In addition, different gene expression patterns of $S B E A$ and $S B E B$ were detected with a range of species, indicating that $S B E B$ is expressed earlier than $S B E A$ in the development stage (Gao et al. 1996; Larsson et al. 1998; Morell et al. 1997; Mutisya et al. 2003).

$$
\text { To fit the rapid development of the lotus processing industry, the work of breeding lotus }
$$
with high starch content is extremely urgent. Therefore, many studies have focused on the starch of lotus. The ADPase and GBSS genes of lotus were isolated and characterized, but little information is currently available about the NnSBE gene (Cheng et al. 2014; Liang-Jun et al. 2006; Lu et al. 2012). For researching the NnSBEs further, this study undertook the isolation of cDNA and genomic clones by encoding two related $S B E$ genes from lotus. Then, genomic variation and evolution were analyzed using DNA and protein sequences of the two NnSBEs. Expression patterns and the affinity of two isozymes were described, as well as the enzyme activity of both NnSBEs in development and different tissues. These data provide valuable information for understanding the processes involved in starch synthesis, and offer some fundamental information for further study about improving the edible quality of lotus.

\section{Material and methods}

\section{Plant material and treatments}

Nelumbo nucifera cv. Taikong lotus 36, the highest strain of selective lotus breed after space 
mutagenesis, was selected in this study (Wu et al. 2007). Seeds were sprouted by soaking in water for germination. Five days after, plants were provided with $50 \mathrm{~cm}$ depth pots in a greenhouse for the entire growing season. Functional leaves, petiole, rhizomes and roots were separately collected in the $8^{\text {th }}$ week, $10^{\text {th }}$ week, $12^{\text {th }}$ week. Seeds from plants at $12,16,20,24$ and 28 DAF (days after fertilization) were also collected from the Taikong lotus 36 in the genetic experimental base of Wuhan University. Various materials from lotus were quick-frozen in liquid nitrogen, then stored at $-80{ }^{\circ} \mathrm{C}$ for next manipulation. The fresh leaves of 45 lotus individuals (Supplement 1) were collected from the genetic experimental base of Wuhan University and stored in silica gel (Sinopharm, China).

\section{RNA isolation and cDNA synthesis}

Total RNA and genomic DNA were isolated from plant tissue samples using a plant RNA extraction kit and Plant Genomic DNA Kit (TIANGEN China), according to their respective operation manuals. The quantities were subjected to $1 \%$ agarose gel electrophoresis and the results were analyzed using a UV Transilluminator (Eppendorf, Germany). The first-strand cDNA of all materials was constructed using the FastKing RT Kit (with gDNase) (TIANGEN, China). The products were stored at $-20{ }^{\circ} \mathrm{C}$ for later use.

\section{Characterization of a genetic polymorphism}

Genetic polymorphism of $N n S B E$ cDNA from 45 individuals of lotus were also analyzed using the gene-specific primers. PCR reactions were conducted in 50ul volumes containing $2 \mathrm{ul}$ of total cDNA, 5 ul of $10 \times$ PCR buffer, 5 ul of $2 \mathrm{mM}$ dNTPs mixture, $3 \mathrm{ul}$ of $25 \mathrm{mM} \mathrm{MgSO}_{4}, 1.6 \mathrm{ul}$ of 10 pM of each primer, $1 \mathrm{ul}$ of $1 \mathrm{U} / \mu 1 \mathrm{KOD}$ DNA polymerase (TOYOBO, Japan) and $30.8 \mu \mathrm{ddH}_{2} \mathrm{O}$, 
106 for a total volume of $50 \mu$ l. Amplification conditions followed the two-step amplification

107 procedure: $94{ }^{\circ} \mathrm{C}$ for $2 \mathrm{~min}, 36$ cycles of $98^{\circ} \mathrm{C}$ for $10 \mathrm{~s},(\mathrm{Tm}){ }^{\circ} \mathrm{C}$ for $30 \mathrm{~s}$, and $68{ }^{\circ} \mathrm{C}$ for $1 \mathrm{~min}$.

108 The sizes of the PCR products were assessed using 1.0\% agarose gel electrophoresis. PCR

109 products were sequenced by Sanger sequencing (Augct, China). Sequences were aligned by

110 DNAman to find molecular markers.

111 Bioinformatics analysis

112 All sequence data were obtained from the National Center for Biotechnology Information

113 (NCBI) GenBank database (http://www.ncbi.nlm.nih.gov/). All primers were designed by Primer

114 Premier 5.0v. Genomic structures were performed with the program Gene Structure Display

115 Server 2.0 (http://gsds.cbi.pku.edu.cn/) (Hu et al. 2015). The GO (Gene Ontology,

116 http://www.geneontology.org) was used for annotation of gene products. The conserved domains

117 were predicted by Pfam sever (http://pfam.xfam.org/search/sequence;) (Finn et al. 2016). All

118 sequences were aligned using Cluxal-X(Thompson et al. 1997) and DNAman. Subsequently the

119 phylogenetic neighbor-joining tree was generated by MEGA6.0v (Tamura et al. 2013). The

120 bootstrap consensus tree inferred from 1,000 replicates was taken to depict the evolutionary

121 history of the analyzed taxa. The $\mathrm{H}_{\mathrm{O}}, \mathrm{H}_{\mathrm{E}}$, Shannon Index was calculated by popGen32 (Nei

122 1978; Nei, Li 1973; Nei, Li 1979). A dendrogram of the cluster analysis was based on Nei's

123 genetic distance using the UPGMA method.

124 Real-time PCR analysis

125 The cDNA of reverse transcription was diluted for 1:10 and used for RT-PCR and qRT-PCR

assays. A house-keeping gene, $C Y P$ (cyclophilin, GenBank accession no.EU131153), was

Peer) reviewing PDF | (2019:03:36185:3:0:NEW 30 Jul 2019) 
127

128

129

130

131

132

133

134

135

136

137

138

139

140

141

142

143

144

145

146

147

selected as the reference gene in this experiment. The primers of $C Y P$ were based on the sequence of CDS and designed by Primer Primer 5.0 (Table 1). The total PCR reaction mixture contained $2 \mu \mathrm{l}$ cDNA (1:10 diluted), $0.4 \mu \mathrm{l}$ forward primer $(10 \mathrm{M}), 0.4 \mu 1$ reverse primer $(10 \mathrm{M})$, $10 \mu 12 \times$ SYBR qPCR Master Mix (with ROX Premixed) (Vazyme, China) and $7.2 \mu 1 \mathrm{ddH}_{2} \mathrm{O}$, for a total volume of $20 \mu \mathrm{l}$. For the qRT-PCR experiment, the two-step amplification procedure was used: $95^{\circ} \mathrm{C}$ for $10 \mathrm{~min}$, followed by 40 cycles of $95{ }^{\circ} \mathrm{C}$ for $15 \mathrm{~s}$ and $60{ }^{\circ} \mathrm{C}$ for $1 \mathrm{~min}$. The relative gene expression data was calculated using the $2^{-\Delta \Delta \mathrm{Ct}}$ method with the guidance of the StepOne software v2.1 (ABI, US). The experimental design followed MIQE (minimum information for publication of quantitative real-time PCR experiments) (Bustin et al. 2010; Bustin et al. 2009). All measurements were processed three times for biological and technical paralleled repetition.

\section{Construction of plasmids}

The full length CDS of $N n S B E I$ and $N n S B E I I I$, which were cloned from lotus, were subcloned into the plasmids $\mathrm{pET}-28 \mathrm{a}$ and $\mathrm{pET}-32 \mathrm{a}$ respectively. The $\mathrm{pET}-28 \mathrm{a}-N n S B E I$ was generated using the following primers:5' - CCCAAGCTTATGTACAGTTTTTCTGGGT-3' (HindIII site underlined), and 5'-CATGCCATGGTCAGTCATCCAATCCCA-3' (Nco I site underlined). The pET-32a-NnSBEIII was obtained by primers: 5'-

CGGGATCCATGGCTACTACAGTTGCGCT-3' (BamHI site underlined) and 5'GCGATATCTCATATTCGCAAAATCCGAG-3' (EcoR V site underlined). The full length and sequence of the nucleotide acid of the inserted gene in the extracted recombinant plasmid were completely identical to the genes. Then, the different recombinant plasmids were transformed into Escherichia coli BL21 (DE3) (TransGen Biotech, China) for expressing and into DH5 $\alpha$ for 
148 storing.

149 Enzyme activity assay

150 Cheng et al.'s protocol of measuring SBE activity was used in this study(Cheng et al. 2001).

151 First, total enzyme isolation: about $0.4 \mathrm{~g}$ powder of plant material was added into a $4 \mathrm{ml}$

152

153

154

155

156

157

158

159

160

161

162

163

164

165

166

167

168

HEPES-NaOH (PH7.5) buffer. After proper shaking, the tube was centrifuged at $10000 \mathrm{~g}$ for 15

min, and supernatant was extracted to check the enzyme activity of SBE. We took $100 \mu 1$

dilution, added 1280 ul of HEPES-NaOH (PH7.5) buffer, and 120 ul $0.75 \%$ of soluble starch.

Then we incubated the total reaction mixture at $37^{\circ} \mathrm{C}$, and gave it a water bath for $20 \mathrm{~min}$. Next,

we gave it a boiling water bath for $1 \mathrm{~min}$ to stop the reaction, diluted the mixture with $2 \mathrm{ml}$ water

(containing $0.2 \% \mathrm{HCl})$, added $150 \mathrm{ul}$ of an iodine solution $\left(0.1 \% \mathrm{I}_{2}-1 \% \mathrm{KI}\right)$, blending it at room

temperature for $10 \mathrm{~min}$. The boiled crude enzyme was used as the control. Finally, we measured

absorbance at $660 \mathrm{~nm}$. The enzyme activity of SBE was expressed as a percentage of decrease in

absorbance at the wavelength of $660 \mathrm{~nm}$ to be compared with the control. All measurements

were processed three times for biological and technical paralleled repetition.

\section{The affinity of two isozymes that bind amylopectin and amylose assay}

Recombinant proteins were expressed in the Escherichia coli BL21(DE3) cells. The transformed cells were grown in LB at $37^{\circ} \mathrm{C}$ until the OD600 reached $0.6-1.0$, using IPTG to induce expression with a final concentration of $0.5 \mathrm{mM}$, and were further incubated at $16^{\circ} \mathrm{C}$ for $12 \mathrm{~h}$.

Cells were harvested by centrifugation at $12000 \mathrm{rpm}$ for $5 \mathrm{~min}$ at $4{ }^{\circ} \mathrm{C}$. The products were suspended in a buffer containing $10 \mathrm{mM}$ PBS in the radio of $200: 1(\mathrm{ml} / \mathrm{g})$, and cells were disrupted (Diagenode, Belgium) by sonication for $25 \mathrm{~min}$ and centrifuged for $5 \mathrm{~min}$ at $4{ }^{\circ} \mathrm{C}$. We 
169

170

171

172

173

174

175

176

177

178

179

180

181

182

183

184

185

186

187

took $30 \mu$ supernatant, added 0, 12.5, 16, 20, 25, 35 ul 0.75\% amylopectin (Sigma, America) or amylose (Sigma, America), and added HEPES-NaOH (PH7.5) buffer into $90 \mathrm{ml}$. Then the total reaction mixtures were incubated at $37{ }^{\circ} \mathrm{C}$ for $30 \mathrm{~min}$. We diluted the mixture with $100 \mathrm{ul} \mathrm{water}$ (containing $0.2 \% \mathrm{HCl})$, and added $10 \mathrm{ul}$ iodine solution $\left(0.1 \% \mathrm{I}_{2}-1 \% \mathrm{KI}\right)$, blending at room temperature for $10 \mathrm{~min}$. Finally, we measured absorbance of amylopectin at $560 \mathrm{~nm}$ and amylose at $620 \mathrm{~nm}$. The blank pET-28a and pET-32a which were transformed into BL21 and cultured in the same condition were used as the control. The affinity of the two isozymes that bind amylopectin and amylose were measured by enzyme activity. All measurements were processed three times for technical repetition and 2 3 paralleled repetition.

\section{Results}

\section{Cloning of $\mathrm{NnSBE}$ genes}

Based on the reference sequence of whole-genome sequencing, the CDS of two SBE genes were obtained using RT-PCR technique from the embryo of the lotus seed. The CDS of NnSBEI (FJ592190.1) was 2577bp, and the CDS of NnSBEIII (XM_010254179) was 2691bp (Fig. 1). Complete genomic structures of NnSBEI (comprising of 14 exons and 13 introns) and NnSBEIII (comprising of 21 exons and 20 introns) were separately distributed over 14.3 and $32.1 \mathrm{~kb}$. The gene structures are shown in figure 2 and the gene information is shown in Table 2. The cDNA of $N n S B E I$ showed the highest (85\%) identity with Castanea mollissima, and $80-84 \%$ identify with SBEI genes of other plant species, while NnSBEIII showed the highest (85\%) identity with Juglans regia and $80-84 \%$ identity with the others.

The deduced protein of NnSBEI comprised 858 amino acids with a predicted molecular 
190

191

192

193

194

195

196

197

198

199

200

201

202

203

204

205

206

207

208

209

210

mass of $97.144 \mathrm{kDa}$, and NnSBEIII comprised 896 amino acids with a predicted molecular mass

of $103.135 \mathrm{kDa}$. GO analysis indicated NnSBE participated in biological processes

(GO:0005978) and 1 molecular function (GO:0043169; GO:0003844; GO:0004553). Pfam

analysis showed that NnSBEs have three domains of secondary structure: the central catalytic A

domain, an $\mathrm{N}$-terminal domain and the $\mathrm{C}$-terminal domain. The central catalytic A-domain of

SBEs is $\alpha$-amylase which covered four conserved amino acid regions and six active sites spread

in those conserved regions respectively. The characterization of catalytic A-domain showed

significant homology (47.83\%) between NnSBEI and NnSBEIII, but highly dissimilar sequences

in N-terminus (21.84\%) and C-terminus (26.47\%).

\section{Phylogenetic analysis}

SBE protein sequences from 20 other species were used for phylogenetic analysis, shown in

figure 3. The NJ phylogenetic tree indicates that SBEs in these plants could be classified into two

families: SBE A and SBE B. SBE A was further divided into four classes: algae SBEII, dicot

SBEII, monocot SBEII and SBEIII, and SBE B was subdivided into algae, dicot SBEI, monocot

SBEI. NnSBEI belonged to the dicot SBEI of family B; NnSBEIII belonged to the SBEIII class

of family A. Evolutionary divergence reveal that SBEIII came before SBEI, and differentiation

of NnSBE occurred before that of the other dicots, but later than the monocots.

\section{Characterization of genetic diversity}

Genetic diversity was identified based on the ORF of two NnSBE genes from 45 lotus

individuals belonging to four clusters (Supplement 1). This revealed six polymorphic sites from

the coding region: five SNPs in NnSBEIII and one in NnSBEI. The SNPs of NnSBEIII was

Peer) reviewing PDF | (2019:03:36185:3:0:NEW 30 Jul 2019) 
211 analyzed and the detailed parameters of genetic diversity are listed in Table 3. Three SNPs

212 resulted in missense mutations which changed the amino acid sequence, while the other two

213 SNPs were synonymously mutated. The observed heterozygosity ranged from 0.2 to 0.4444 , and

214 the expected heterozygosity ranged from 0.4012 to 0.4583 . The Shannon-Wiener Index ranged

215 from 0.5908 to 0.6508 . In further association analysis of starch content (amylopectin, amylose,

216 total starch) in lotus seeds, no SNP showed highly significant associations. Total of 12 genotypes

217 were detected in those 45 individuals, each cluster had different several kinds of genotypes

218 (Supplement 1). A homozygous genotype (AA GG GG AA GG) of NnSBEIII was observed in

219 most individuals in seed lotusand a haplotype (A G G A G) was identified from seed lotus.

220 Cluster analysis according to the UPGMA method is shown in figure 4 . The 45 individuals of

221 lotus were copolymerized into three classes. The first class can be divided into two subclasses

222 with a similarity coefficient of 9.8 , and most seed lotus showed together in a same subgroup.

223 These results paved a way to apply the useful allelic variations or gene haplotypes in cultivar

224 lotus and quality breed programs.

225 Expression pattern

226 The temporal and spatial expression of both genes were analyzed to investigate their expression

227 patterns. The results of qRT-PCR demonstrated that the transcriptional expression level of

$228 N n S B E I$ and $N n S B E I I I$ was detectable in all tissues. Tissue-specific expression analysis showed

229 that the highest transcript levels of NnSBEI and NnSBEIII were observed in leaves. The

230 transcript level of $N n S B E I$ was higher in rhizomes while $N n S B E I I I$ expressed strongly in

231 petioles. The expression profile of $N n S B E I$ in the rhizome showed strong temporal differences,

Peer] reviewing PDF | (2019:03:36185:3:0:NEW 30 Jul 2019) 
232 and the relative expression level increased gradually from initial development to late stage.

233 NnSBEIII showed temporal differences in the petiole, which enhanced in the middle and

234 decreased in the late stage (Fig.5). During the seed embryo developing stage, NnSBEI and

235 NnSBEIII expressed significant differences. Transcripts of NnSBEIII reached the peak at 20 DAF

236 in the middle of development stage, and then decreased gradually, while NnSBEI increased in 16

237 DAF to 28 DAF and expressed strongly in the mid-late developmental stage (Fig.6). In the peak

238 stage, NnSBEI expressed ten times higher than NnSBEIII.

239

240

241

242

243

244

245

246

247

248

249

250

251

252

\section{Dynamic changes of enzyme activities}

The dynamic changes of enzyme activity of the SBEs were analyzed in different temperatures, tissues and developing stages. Incubation in different temperatures revealed that the highest enzyme activity was generated under $37^{\circ} \mathrm{C}$. The enzyme activity of inter-organizational measurement and assessment showed the highest catalytic activity in leaves, followed by rhizomes and petioles which increased steadily, and activity in the roots was the weakest. During seed development, enzyme activity increased rapidly, and the activity peak appeared at 20 DAF, then decreased slightly (Fig. 7).

\section{The affinity of two isozymes that bind amylopectin and amylose}

To explore the affinity activity, recombinant DNA techniques were used to generate the pET28a-NnSBEI and pET-32a-NnSBEIII plasmids. Testing of the inducible expression vector showed that both proteins were soluble, and the apparent molecular weights of pET-28a-NnSBEI and pET-32a-NnSBEIII were about $105 \mathrm{kDa}$ and $120 \mathrm{kDa}$ (with His tag) respectively. The affinity activity of NnSBEI and NnSBEIII to amylopectin and amylose were assayed at various 
starch concentrations. As we can see in figure 8, the activity of both isozymes correlated with the

types and concentration of substrate. Rate of reaction changed with the increase of the substrate

concentration until the enzyme was saturated. NnSBEI showed higher affinity activity when the

substrates were amylose and amylopectin. However, another isozyme, NnSBEIII, only worked

on amylopectin, and the branching efficiency was only half of NnSBEI.

258

259

260

261

262

263

264

265

266

267

268

269

270

271

272

273

\section{Discussion}

Starch is an important edible component in lotus, and the starch branch enzyme is involved in the synthesis of amylopectin. In this study, we focused on the SBE family genes in lotus, and revealed two isoforms of $N n S B E \mathrm{~s}: N n S B E I$ and $N n S B E I I I$. In this study, SBE phylogenetic tree included the SBE gene families from algae, monocots and dicots according to the protein sequences of the sequenced species. Two or three SBE isoforms were isolated from different plants, and divided into two families: family A and family B (Fig. 4). NnSBEI belonged to family $\mathrm{B}$, which has been reported in a range of species. NnSBEIII belonged to family A, which has only been identified in maize, wheat, rice and lotus, and little research has been done about this isoform (Kang et al. 2013; Tian et al. 2009).

Over the last decades, many investigations have been devoted to exploring genomic variation and evolution among different germplasms. Whole genome re-sequencing reveals the evolutionary patterns of sacred lotus, rhizome lotus had the lowest genomic diversity and a closer relationship to wild lotus, whereas the genomes of seed lotus and ornament lotus were admixed (Huang et al. 2018). In this study, genetic diversity and genetic variation of NnSBEIII were investigated among 45 individuals from four lotus subgroups. Wild lotus had the higher 
274 genomic diversity, rhizome lotus was admixed with wild and flower lotus respectively, and lotus 275 seed formed a homozygous single haplotype, which might be the result of continuous selection 276 in the cultivation process of lotus in the long-term evolution process (Doebley, Gaut, Smith 277 2006; Yue, Melamud, Moult 2006). This different performance speculates that the NnSBE gene 278 has more effect on starch accumulation in seed lotus, but less in rhizome lotus.

279 Starch synthesis and accumulation are closely related to photosynthesis. It was found that the 280 AGPase and GBSS genes of lotus, related to starch synthesis, were expressed higher in leaves (Cheng et al. 2014; Lu et al. 2012). As the tissue of photosynthesis, leaves support the first step of synthesizing sugar and meet the carbon demand faster and it is the major tissue for accumulating transient starch. The results of qRT-PCR showed that the two NnSBEs were expressed throughout plant tissues. NnSBEI was strongly activated in the leaves and petiole;

NnSBEIII was highly expressed in the leaves and stems (Fig. 4). The transcriptional level kept rising during the swelling stage in the petiole and rhizome, which represent the photosynthetic tissue and storage tissues respectively. It is possible to adapt to the synthesis of transient starch in photosynthetic tissue, and it is consistent with reserve starch synthesis in storage organs during starch rapid development. This spatial and temporal variation from top to bottom may be related to the process and the transport of starch synthesis to achieve higher efficiency of starch accumulation. Such expression patterns of temporal and spatial controls have also been found in many other species (Tetlow 2010). This spatial and temporal expression pattern of $N n S B E$ s help amylopectin to adapt requirements at different developmental stages. 
295

296

297

298

299

300

301

302

303

304

305

306

307

308

309

310

311

312

313

314

315

is more sensitive to amylose. Likewise, this experiment showed that NnSBEI has higher catalytic activity for amylose and amylopectin, while NnSBEIII expressed catalytic activity only when the substrate was amylopectin. Protein sequences of the SBE genes among a range of species revealed that the SBEI and SBEIII subunits showed homology in their $\alpha$-amylase catalytic domain, but highly dissimilar sequences in N-terminus and C-terminus. Construction of chimeric enzymes out of maize branching enzymes found that the N-terminal determined the specificity of the transferred chain length, and the C-terminal domain participates in the specificity of the substrate (Commuri, Keeling 2001; Hong, Mikkelsen, Preiss 2001; Kuriki, Stewart, Preiss 1997). Therefore the N-terminal region of SBE is essential for maximum enzyme activity and thermostability (Hamada et al. 2007), and C-terminus determines both substrate preference and maximal catalytic activity (Hong, Preiss 2000). We speculated that the difference between enzymatic characteristics of the two subunits are determined by the N-terminus and C-terminus. These differences met the requirements of amylopectin to produce different grades of branches and different sizes of side chains.

Expression and protein structure-activity analysis in the plant kingdom indicated that SBE plays a critical role in affecting the fine structure of amylopectin (Satoh et al. 2003). In another study of developing lotus seeds, a similar conclusion was drawn. In this study, we learned that NnSBEI belong to the SBE B family and tend to transfer longer chains, while NnSBEIII belonged to the SBE A family and prioritized short chain. Higher catalytic activity and expression level of NnSBEI indicated that the long chain was preferred in the transfer during the starch synthesis of lotus seed. Zhuo's research about the molecular structure of lotus seed found 
316 that the branching degree of amylopectin was short, and the glucose residues of side chains were

317 longer, more than 30 (Zheng, Zheng, Zeng 2004). This is consistent with the level of genetic

318 research on $N n S B E$ s. Therefore, transcription and activity of SBEs in lotus have a great influence

319 in the fine structure of amylopectin. Furthermore, the edible quality of lotus seed was affected,

320 making it easy for starch to retrogradate.

321

322

323

324

325

326

327

328

329

330

331

332

333

334

335

336

337

338

339

\section{Conclusion}

This study undertook the preliminary study of $N n S B E$ genes in lotus. Two isoforms which encoding starch branching enzyme, were isolated and characterized from lotus. Genetic diversity was analyzed by SNPs of two $N n S B E$ s, revealed the genetic variation levels among varieties. Difference of expression patterns and the affinity about two isozymes were described, as well as the enzyme activity of SBE in development and different tissues, provided necessary information for understanding of the processes involved in starch synthesis from the level of gene and protein. This study revealed the selection of $N n S B E$ genes during the cultivation process of lotus, and the effect of $N n S B E$ genes on the fine structure of starch in lotus seed. Although the relationships between transcription level, enzyme activity and starch accumulation are complex, our study provides us as much functional information as possible.

\section{References}

Burton Rachel A, Bewley JD, Smith Alison M, Bhattacharyya Madan K, Tatge H, Ring S, Bull V, Hamilton William DO,Martin C. 1995. Starch branching enzymes belonging to distinct enzyme families are differentially expressed during pea embryo development. The Plant Journal 7:3-15. 10.1046/j.1365313X.1995.07010003.x

Bustin SA, Beaulieu J-F, Huggett J, Jaggi R, Kibenge FSB, Olsvik PA, Penning LC,Toegel S. 2010. MIQE précis: Practical implementation of minimum standard guidelines for fluorescence-based quantitative real-time PCR experiments. BMC Molecular Biology 11:74. 10.1186/1471-2199-11-74 
Bustin SA, Benes V, Garson JA, Hellemans J, Huggett J, Kubista M, Mueller R, Nolan T, Pfaffl MW, Shipley GL, Vandesompele J,Wittwer CT. 2009. The MIQE guidelines: minimum information for publication of quantitative real-time PCR experiments. Clin Chem 55:611-622. 10.1373/clinchem.2008.112797

Chen Y, Fan G, Wu H, Wu Y,Mitchell A. 2007. Separation, identification and rapid determination of liensine, isoliensinine and neferine from embryo of the seed of Nelumbo nucifera GAERTN. by liquid chromatography coupled to diode array detector and tandem mass spectrometry. Journal of Pharmaceutical and Biomedical Analysis 43:99-104. https://doi.org/10.1016/j.jpba.2006.06.016

Cheng F, Jiang D, Wu P,Shi C. 2001. The dynamic change of starch synthesis enzymes during the grain filling stage and effects of temperature upon it. Zио wи хие bao 27:201-206.

Cheng N, Zeng X-F, Zheng X-F, Diao Y, Wang Y-W, Xie K-Q, Zhou M-Q,Hu Z-L. 2014. Cloning and characterization of the genes encoding the small and large subunit of the ADP-glucose pyrophosphorylase in lotus (Nelumbo nucifera Gaertn). Acta Physiologiae Plantarum 37. 10.1007/s11738-014-1734-2

Commuri PD,Keeling PL. 2001. Chain-length specificities of maize starch synthase I enzyme: studies of glucan affinity and catalytic properties. The Plant Journal 25:475-486. 10.1046/j.1365-313x.2001.00955.x

Doebley JF, Gaut BS,Smith BD. 2006. The Molecular Genetics of Crop Domestication. Cell 127:1309-1321. https://doi.org/10.1016/j.cell.2006.12.006

Finn RD, Coggill P, Eberhardt RY, Eddy SR, Mistry J, Mitchell AL, Potter SC, Punta M, Qureshi M, SangradorVegas A, Salazar GA, Tate J,Bateman A. 2016. The Pfam protein families database: towards a more sustainable future. Nucleic Acids Research 44:D279-285. 10.1093/nar/gkv1344

Fujita N, Goto S, Yoshida M, Suzuki E,Nakamura Y. 2008. The Function of Rice Starch Synthase I Expressed in Escherichia coli.

Gao M, Fisher DK, Kim K-N, Shannon JC,Guiltinan MJ. 1996. Evolutionary conservation and expression patterns of maize starch branching enzyme I and IIb genes suggests isoform specialization. Plant Molecular Biology 30:1223-1232. 10.1007/BF00019554

Guan H, Li P, Imparl-Radosevich J, Preiss J,Keeling P. 1997. Comparing the Properties ofEscherichia coliBranching Enzyme and Maize Branching Enzyme. Archives of Biochemistry and Biophysics 342:92-98. https://doi.org/10.1006/abbi.1997.0115

Guo HB. 2009. Cultivation of lotus (Nelumbo nucifera Gaertn. ssp. nucifera) and its utilization in China. Genetic Resources and Crop Evolution 56:323-330. 10.1007/s10722-008-9366-2

Hamada S, Ito H, Ueno H, Takeda Y,Matsui H. 2007. The N-terminal region of the starch-branching enzyme from Phaseolus vulgaris L. is essential for optimal catalysis and structural stability. Phytochemistry 68:13671375. https://doi.org/10.1016/j.phytochem.2007.02.024

Hong S, Mikkelsen R,Preiss J. 2001. Analysis of the Amino Terminus of Maize Branching Enzyme II by Polymerase Chain Reaction Random Mutagenesis. Archives of Biochemistry and Biophysics 386:62-68. https://doi.org/10.1006/abbi.2000.2179

Hong S,Preiss J. 2000. Localization of C-Terminal Domains Required for the Maximal Activity or for Determination of Substrate Preference of Maize Branching Enzymes. Archives of Biochemistry and Biophysics 378:349-355. https://doi.org/10.1006/abbi.2000.1845

Hu B, Jin J, Guo A-Y, Zhang H, Luo J,Gao G. 2015. GSDS 2.0: an upgraded gene feature visualization server. Bioinformatics 31:1296-1297. 10.1093/bioinformatics/btu817

Huang L, Yang M, Li L, Li H, Yang D, Shi T,Yang P. 2018. Whole genome re-sequencing reveals evolutionary 
381

382

383

384

385

386

387

388

389

390

391

392

393

394

395

396

397

398

399

400

401

402

403

404

405

406

407

408

409

410

411

412

413

414

415

416

417

418

419

420

421

patterns of sacred lotus (Nelumbo nucifera). Journal of Integrative Plant Biology 60:2-15.

10.1111/jipb.12606

Jeon JS, Ryoo N, Hahn TR, Walia H,Nakamura Y. 2010. Starch biosynthesis in cereal endosperm. Plant Physiology and Biochemistry 48:383-392. 10.1016/j.plaphy.2010.03.006

Kang G, Li S, Zhang M, Peng H, Wang C, Zhu Y,Guo T. 2013. Molecular cloning and expression analysis of the starch-branching enzyme III gene from common wheat (Triticum aestivum ). Biochemical Genetics 51:377386. 10.1007/s10528-013-9570-4

Kuriki T, Stewart DC,Preiss J. 1997. Construction of Chimeric Enzymes out of Maize Endosperm Branching Enzymes I and II. Journal of Biological Chemistry 272:28999-29004. 10.1074/jbc.272.46.28999

Larsson C-T, Khoshnoodi J, Ek B, Rask L,Larsson H. 1998. Molecular cloning and characterization of starchbranching enzyme II from potato. Plant Molecular Biology 37:505-511. 10.1023/A:1005908305456

Liang-Jun LI, Zhang XD, Pan EC, Sun L, Xie K, Li GU,Cao BS. 2006. Relationship of Starch Synthesis with It's Related Enzymes'Activities During Rhizome Development of Lotus(Nelumbo nucifera Gaertn). Scientia Agricultura Sinica.

Lu Y, Li L, Zhou Y, Gao Q, Liang G, Chen X, Qi X. 2012. Cloning and Characterization of the Wx Gene Encoding a Granule-Bound Starch Synthase in Lotus (Nelumbo nucifera Gaertn). Plant Molecular Biology Reporter 30:1210-1217. 10.1007/s11105-012-0430-x

Martin C,Smith AM. 1995. Starch biosynthesis. The Plant Cell 7:971-985.

Morell MK, Blennow A, Kosar-Hashemi B,Samuel MS. 1997. Differential Expression and Properties of Starch Branching Enzyme Isoforms in Developing Wheat Endosperm. Plant Physiology 113:201.

Mutisya J, Sathish P, Sun C, Andersson L, Ahlandsberg S, Baguma Y, Palmqvist S, Odhiambo B, Åman Per,Jansson C. 2003. Starch branching enzymes in sorghum (Sorghum bicolor) and barley (Hordeum vulgare): Comparative analyses of enzyme structure and gene expression. Journal of Plant Physiology 160:921-930. https://doi.org/10.1078/0176-1617-00960

Nei M. 1978. ESTIMATION OF AVERAGE HETEROZYGOSITY AND GENETIC DISTANCE FROM A SMALL NUMBER OF INDIVIDUALS. Genetics 89:583.

Nei M,Li W-H. 1973. LINKAGE DISEQUILIBRIUM IN SUBDIVIDED POPULATIONS. Genetics 75:213.

Nei M,Li WH. 1979. Mathematical model for studying genetic variation in terms of restriction endonucleases. Proceedings of the National Academy of Sciences 76:5269.

Satoh H, Nishi A, Yamashita K, Takemoto Y, Tanaka Y, Hosaka Y, Sakurai A, Fujita N,Nakamura Y. 2003. StarchBranching Enzyme I-Deficient Mutation Specifically Affects the Structure and Properties of Starch in Rice Endosperm. Plant Physiology 133:1111.

Shen-Miller J. 2002. Sacred lotus, the long-living fruits of $<\mathrm{I}>$ China Antique $</ \mathrm{I}>$. Seed Science Research 12:131143. $10.1079 / \mathrm{ssr} 2002112$

Shen-Miller J, Mudgett MB, Schopf JW, Clarke S,Berger R. 1995. Exceptional Seed Longevity and Robust Growth: Ancient Sacred Lotus from China. American Journal of Botany 82:1367-1380. 10.2307/2445863

Slattery CJ, Kavakli IH,Okita TW. 2000. Engineering starch for increased quantity and quality. Trends in Plant Science 5:291-298. https://doi.org/10.1016/S1360-1385(00)01657-5

Subasinghe RM, Liu F, Polack UC, Lee EA, Emes MJ,Tetlow IJ. 2014. Multimeric states of starch phosphorylase determine protein-protein interactions with starch biosynthetic enzymes in amyloplasts. Plant Physiology and Biochemistry 83:168-179. https://doi.org/10.1016/j.plaphy.2014.07.016

Peer) reviewing PDF | (2019:03:36185:3:0:NEW 30 Jul 2019) 
422

423

424

425

426

427

428

429

430

431

432

433

434

435

436

437

438

439

440

441

442

443
Tamura K, Stecher G, Peterson D, Filipski A,Kumar S. 2013. MEGA6: Molecular Evolutionary Genetics Analysis version 6.0. Molecular Biology and Evolution 30:2725-2729. 10.1093/molbev/mst197

Tetlow Ian J,Emes Michael J. 2014. A review of starch-branching enzymes and their role in amylopectin biosynthesis. IUBMB Life 66:546-558. 10.1002/iub.1297

Tetlow IJ. 2010. Starch biosynthesis in developing seeds. Seed Science Research 21:5-32.

$$
10.1017 / \text { S0960258510000292 }
$$

Thompson JD, Gibson TJ, Plewniak F, Jeanmougin F,Higgins DG. 1997. The CLUSTAL_X Windows Interface: Flexible Strategies for Multiple Sequence Alignment Aided by Quality Analysis Tools. Nucleic Acids Research 25:4876-4882. 10.1093/nar/25.24.4876

Tian Z, Qian Q, Liu Q, Yan M, Liu X, Yan C, Liu G, Gao Z, Tang S, Zeng D, Wang Y, Yu J, Gu M,Li J. 2009. Allelic diversities in rice starch biosynthesis lead to a diverse array of rice eating and cooking qualities. Proceedings of the National Academy of Sciences of the United States of America 106:21760-21765. 10.1073/pnas.0912396106

Wu J-Z, Zheng Y-B, Chen T-Q, Yi J, Qin L-P, Rahman K,Lin W-X. 2007. Evaluation of the quality of lotus seed of Nelumbo nucifera Gaertn from outer space mutation. Food Chemistry 105:540-547. https://doi.org/10.1016/j.foodchem.2007.04.011

Yue P, Melamud E,Moult J. 2006. SNPs3D: Candidate gene and SNP selection for association studies. BMC Bioinformatics 7:166. 10.1186/1471-2105-7-166

Zheng BD, Zheng JG,Zeng CX. 2004. Study on Three Functional Components of Chinese Main Lotus Seed Varieties. Acta Nutrimenta Sinica. 
Figure 1

The amplication of cDNA fragments of NnSBEs.

The amplication of cDNA fragments of NnSBEs NnSBEI and NnSBEIII using RT-PCR

experiments. The products were analyzed by electrophoresis on $1.0 \%$ agarose gels, DL 5000

DNA marker.

\section{Marker NnSBEI NnSBEIII}

\section{$5000 \mathrm{bp}$}

$3000 \mathrm{bp}$

$2000 \mathrm{bp}$

$1500 \mathrm{bp}$

$1000 \mathrm{bp}$

$750 \mathrm{bp}$ 
Figure 2

The gene structure of NnSBEI and NnSBEIII.

The blue boxes represent UTR, black boxes represent the exons, thick line represent intros.
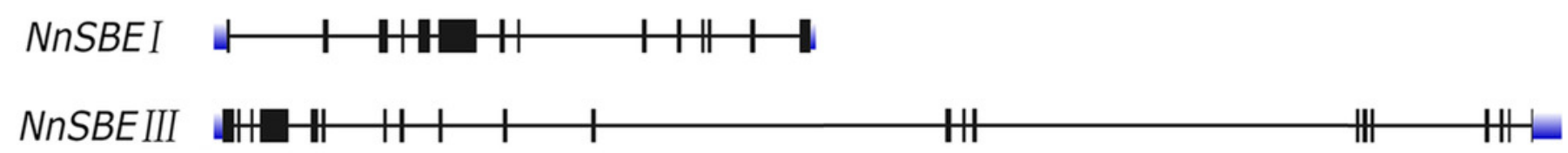

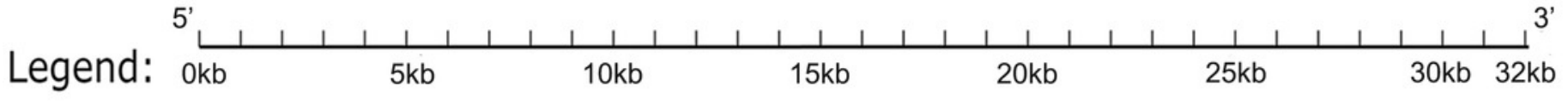

Exon $=$ UTR — Intron 


\section{Figure 3}

Phylogenetic analysis of the SBEs family.

The dendrogram was constructed using MEGA6.0 software with the neighbor-joining method. Sequences aligned included the SBE protein sequences of 20 other species, which identified or predicted from NCBI database were used for phylogenetic analysis. Different color regions represent two subclades of SBEs: the blue region cover SBE A family, and the gray cover SBE B family. The NnSBEs were labeled with "๑". 


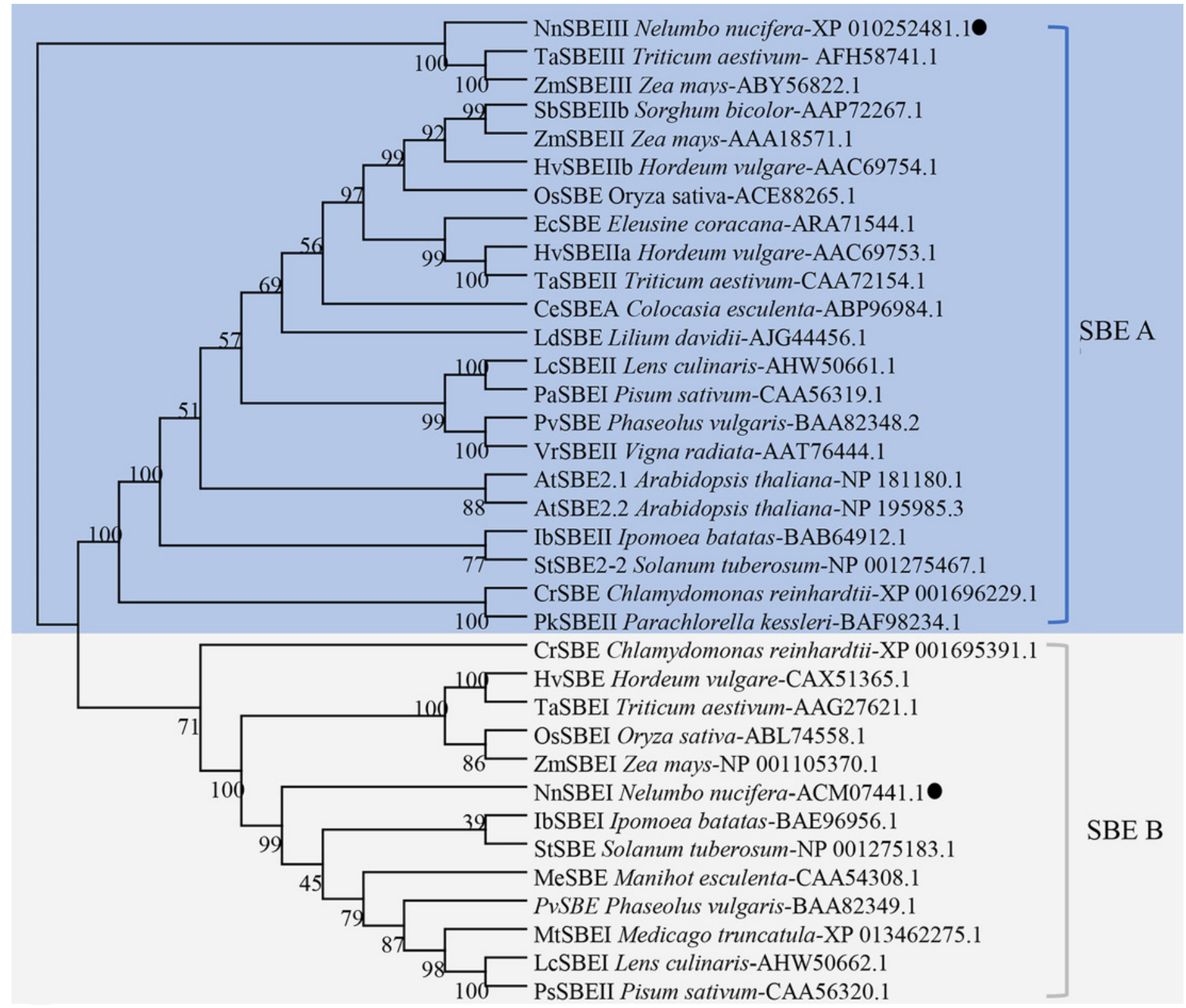


Figure 4

Dendrogram of 45 individuals lotus based on SNP data of NnSBEIII.

Dendrogram based Nei's genetic distance and the UPGMA method was using for Cluster analysis. The 45 individuals of lotus were copolymerized into three classes. The number of individuals were shown in the supplementary 1. 


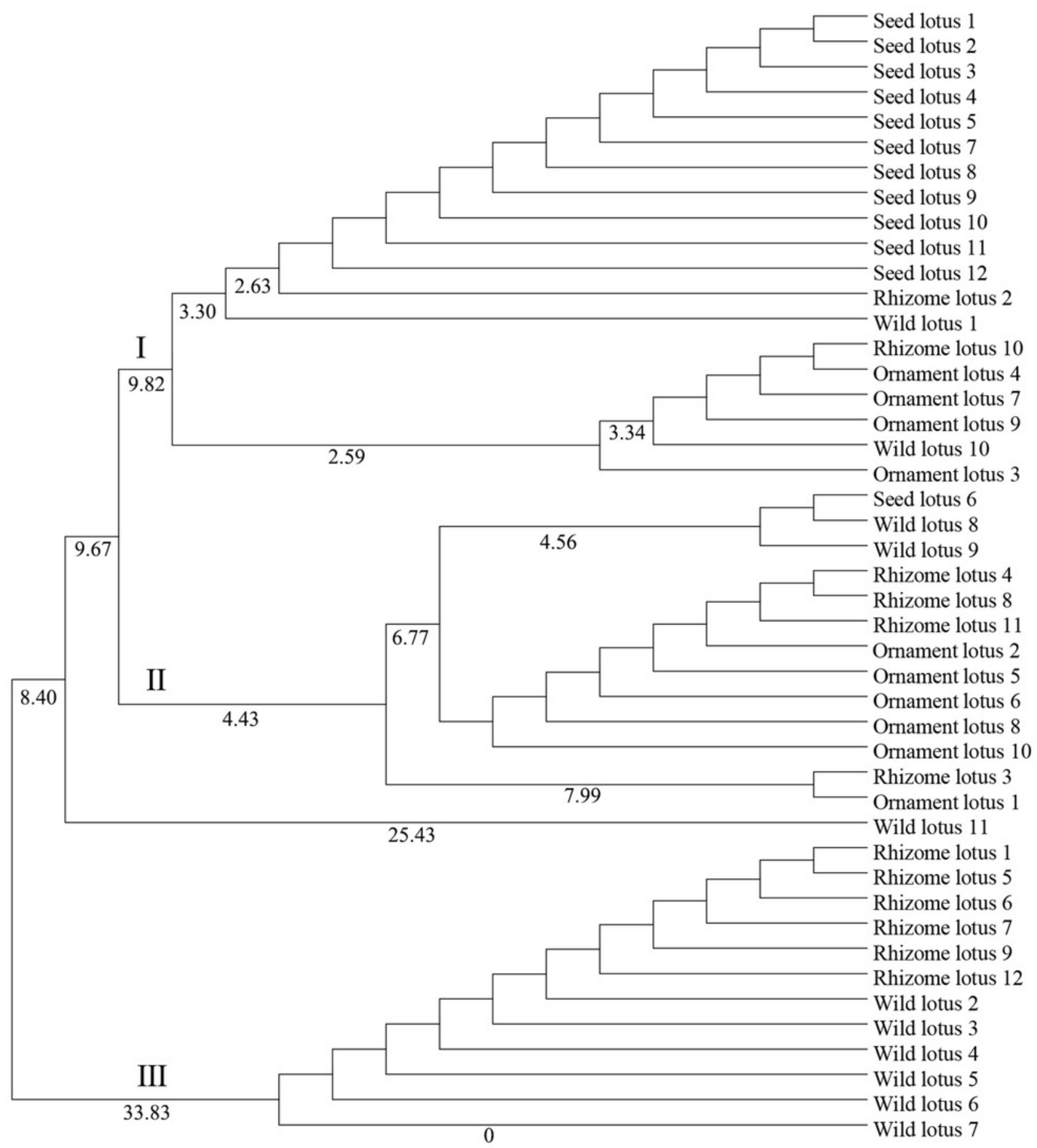

AGGAG

AGGAG

AGGAG

AGGAG

AGGAG

AGGAG

AGGAG

AGGAG

AGGAG

AGGAG

AGGAG

AGGAG

AGRAG

ARRAG

ARRAG

ARRAG

ARRAG

ARRAG

ARRRG

RGRRR

RGRRR

RGRRR

RRRRR

RRRRR

RRRRR

RRRRR

RRRRR

RRRRR

RRRRR

RRRRR

GRRRG

GRRAG

GGGAA

AAGAG

AAGAG

AAGAG

AAGAG

AAGAG

AAGAG

GGAGA

GGAGA

GGAGA

GGAGA

GGAGA

GGAGA 


\section{Figure 5}

Tissue-differential expression of the NnSBEs.

The column chart confirmed expression pattern of leaves, petiole, rhizomes, roots which collected in 8th week after sowing at the early swelling stage $(a, d)$, collected in 10th week after sowing at the middle swelling stage (b, e), collected in 12th week after sowing at the later swelling stage $(c, f)$ in lotus. The gray boxes represent NnSBEI and the lightgray represent NnSBEIII. Error bars indicate standard error $(n=3)(p<0.05)$.
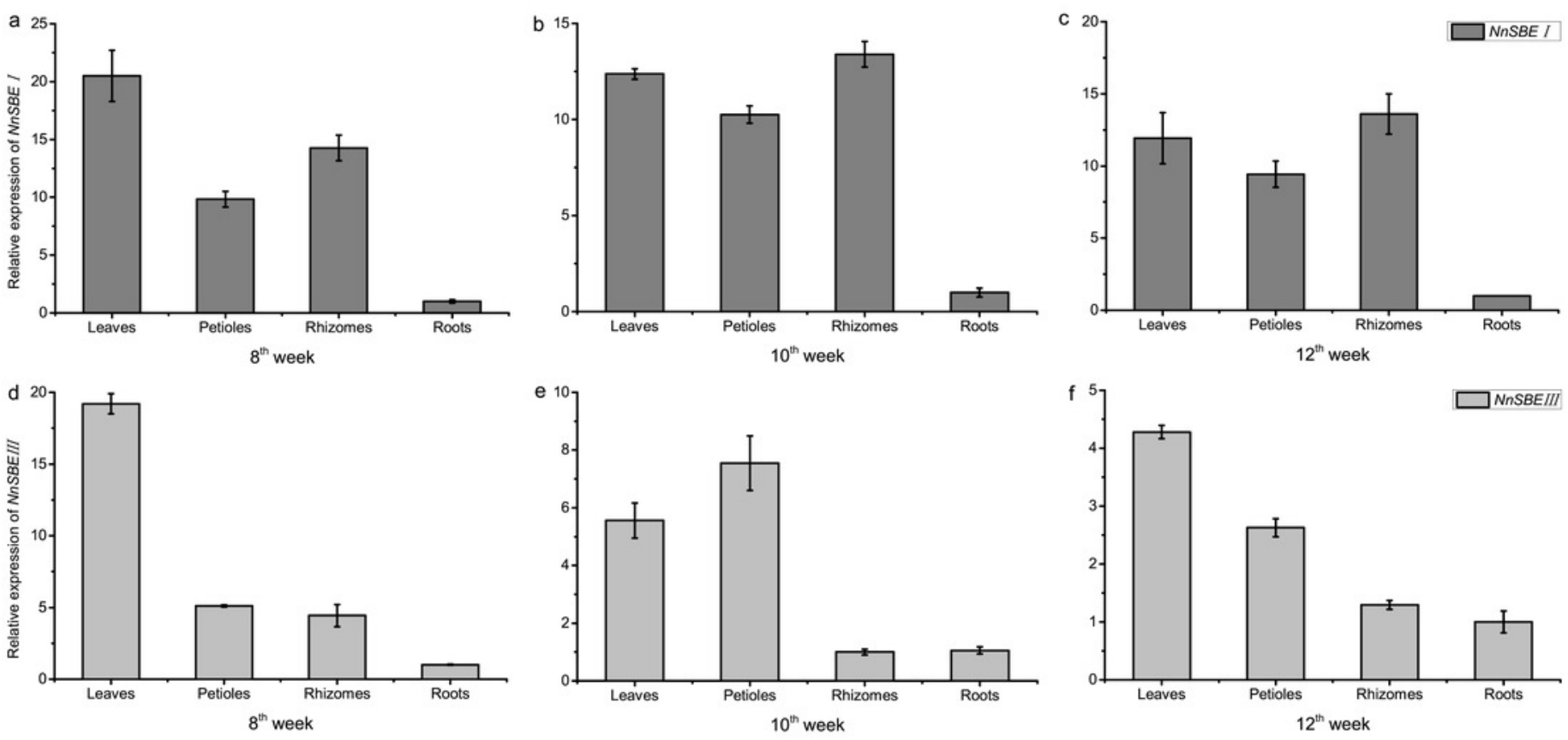
Figure 6

Expressed tendency of the NnSBEs during developing seed.

Relative expression of the NnSBEs were analyzed at 12, 16, 20, 24, 28 DAF. The gray boxes represent NnSBEI (a) and the lightgray represent NnSBEIII (b). Error bars indicate standard error $(n=3)(p<0.05)$.

a

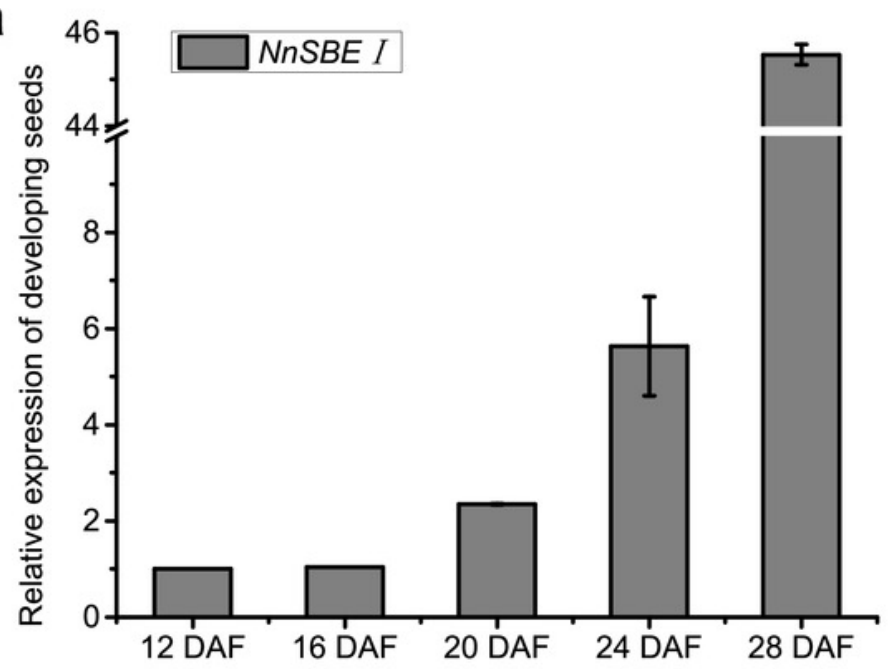

b

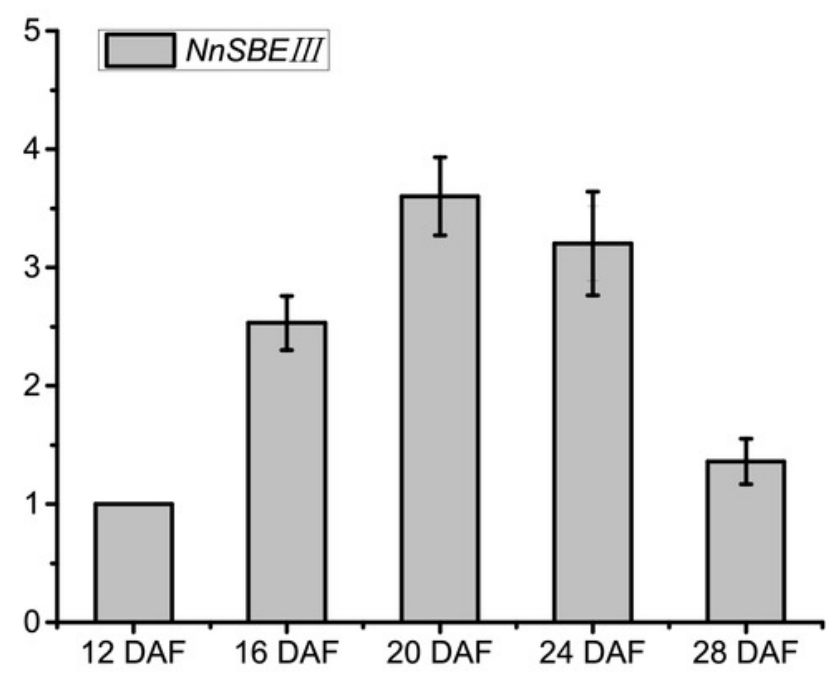




\section{Figure 7}

Enzyme activity of NnSBE.

Tissue-differential enzyme activity of NnSBE in leaves, petiole, rhizomes, roots which collected in 8th week after sowing at the early swelling stage, 10th week after sowing at the middle swelling stage, 12th week after sowing at the later swelling stage, and the different colors (black, red, blue, purple) represent various organs(leaf, petiole, rhizome and root) in an orderly way from top to bottom (a). Enzyme activity of developing seed of NnSBE at 12, $16,20,24,28 \mathrm{DAF}$, the green lines represent seed(b). Error bars indicate standard error $(\mathrm{n}=$ 3) $(p<0.05)$.
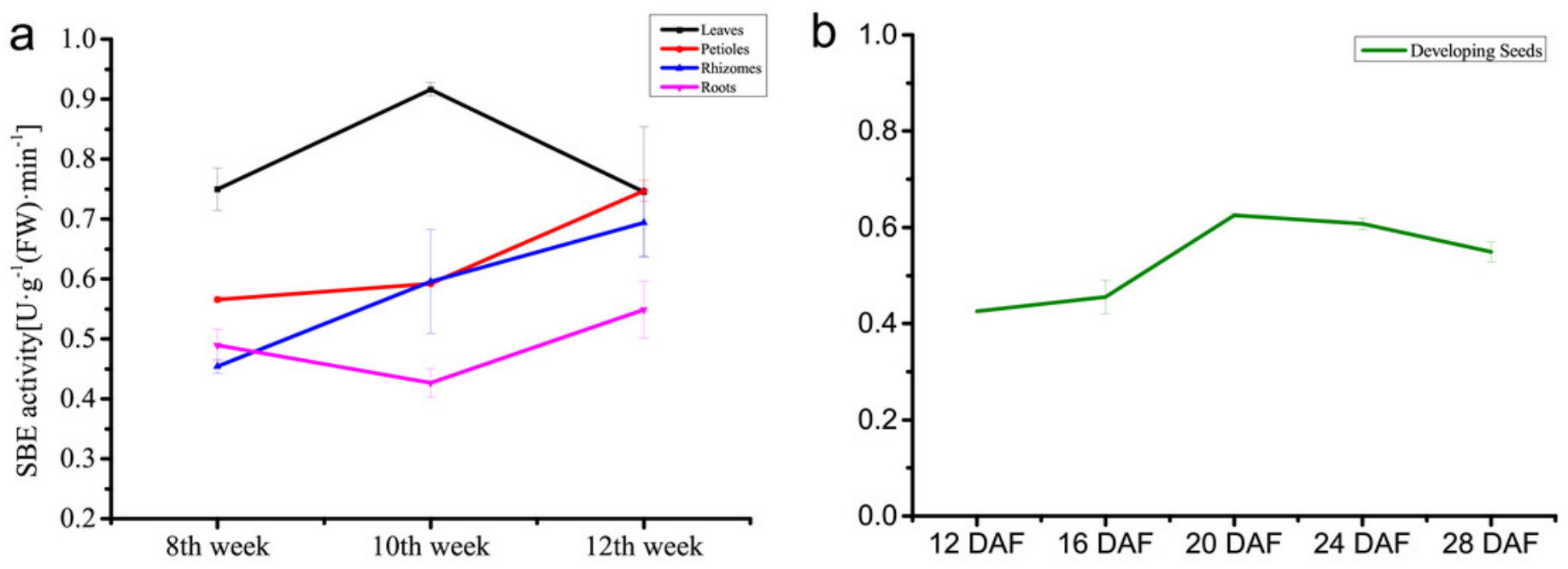
Figure 8

The rate of change in absorbance about NnSBEl and NnSBEIII reacted among different substrate concentration.

The substrate is amylopectin (a); the substrate is amylose(b). The black lines represent NnSBEl; the red line represents NnSBEIII.
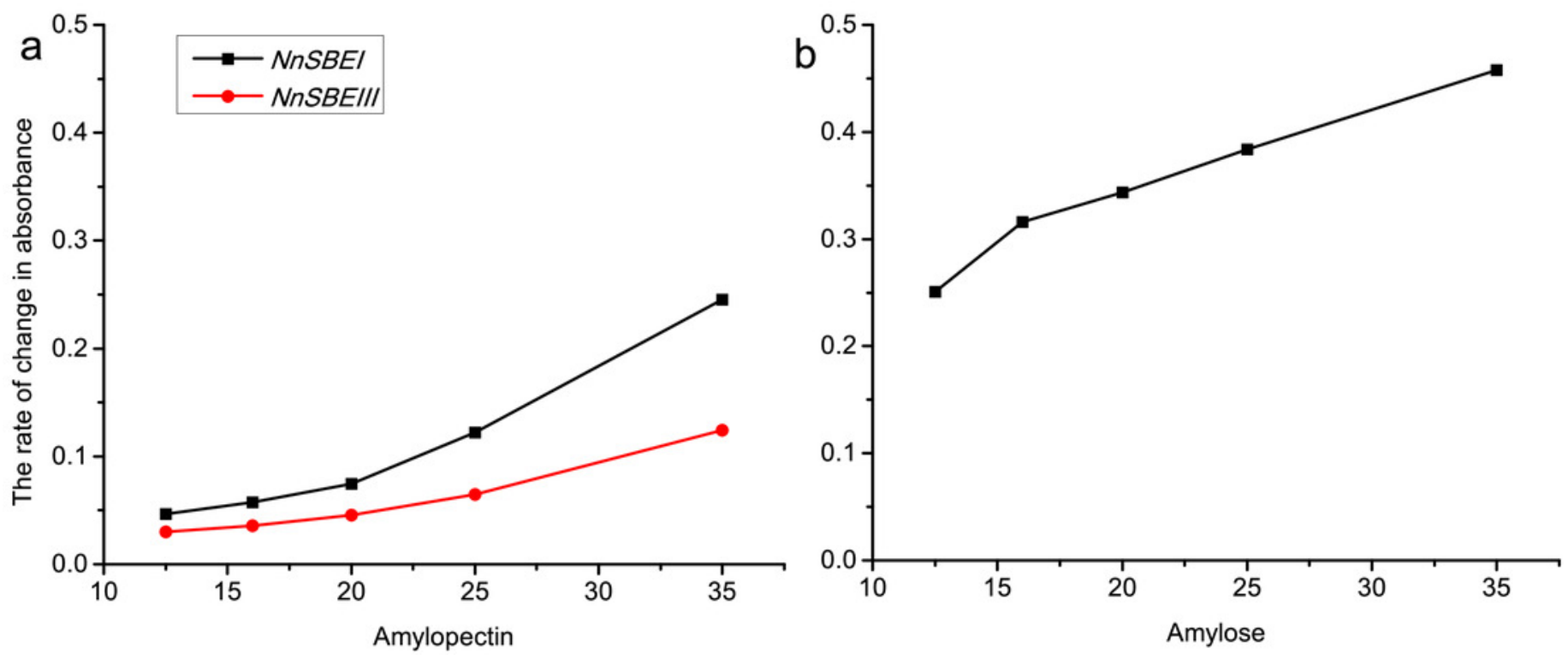
Table $\mathbf{1}$ (on next page)

Primers used in qRT-PCR 


\begin{tabular}{|c|c|c|c|c|}
\hline Gene & $\begin{array}{l}\text { Sequence forward \& reverse primers } \\
\left(5^{\prime}-3^{\prime}\right)\end{array}$ & $\begin{array}{l}\text { Amplicon } \\
\text { length (bp) }\end{array}$ & $\mathbf{R}^{2}$ & $\begin{array}{l}\text { Primer } \\
\text { efficiency }\end{array}$ \\
\hline qCYP-F & GTACCCAGAAGAATGCCCTA & \multirow[t]{2}{*}{102} & \multirow[t]{2}{*}{0.998} & \multirow[t]{2}{*}{96.222} \\
\hline $\mathrm{q} C Y P-\mathrm{R}$ & ATGAAGCCCTTGATGACTCG & & & \\
\hline qNnSBEI-F & GTAGACCATTTCACATCGC & \multirow[t]{2}{*}{114} & \multirow[t]{2}{*}{0.999} & \multirow[t]{2}{*}{93.132} \\
\hline qNnSBEI-R & TAATAAGCCACACATGTACGAG & & & \\
\hline $\mathrm{q} N n S B E I I I-F$ & TATGCATGGCTAGTTCCAC & \multirow[t]{2}{*}{110} & \multirow[t]{2}{*}{0.999} & \multirow[t]{2}{*}{86.246} \\
\hline qNnSBEIII-R & TTATGCCAAAATGCCTCGT & & & \\
\hline
\end{tabular}

1 Table 1 Primers used in qRT-PCR 
Table 2 (on next page)

Gene information of NnSBEI and NnSBEIII 


\begin{tabular}{|l|l|l|l|l|l|l|}
\hline $\begin{array}{l}\text { Gene } \\
\text { name }\end{array}$ & Gene ID & $\begin{array}{l}\text { Genomic } \\
\text { length(kb) }\end{array}$ & $\begin{array}{l}\text { ORF length } \\
\text { (bp) }\end{array}$ & $\begin{array}{l}\text { Number } \\
\text { of exons }\end{array}$ & $\begin{array}{l}\text { Number } \\
\text { of intros }\end{array}$ & $\begin{array}{l}\text { Number of } \\
\text { amino acid (Aa) }\end{array}$ \\
\hline NnSBEI & 104603742 & 14.3 & 2352 & 14 & 13 & 783 \\
\hline NnSBEIII & 104594060 & 32.1 & 2691 & 21 & 20 & 896 \\
\hline
\end{tabular}

1 Table 2 Gene information of NnSBEI and NnSBEIII 


\section{Table 3(on next page)}

Genetic diversity based on SNPs of NnSBEIII in the test population.

$H_{0}$ : the observed heterozygosity; $H_{E}$ : the expected heterozygosity. 


\begin{tabular}{|c|c|c|c|c|c|c|c|c|}
\hline \multirow{2}{*}{$\begin{array}{l}\text { SNPs of } \\
N n S B E I I I\end{array}$} & \multirow{2}{*}{$\begin{array}{l}\mathrm{Aa} \\
\mathrm{M}\end{array}$} & \multicolumn{2}{|c|}{ Allelic frequency } & \multicolumn{2}{|c|}{$\begin{array}{l}\text { Genotypic } \\
\text { frequency }\end{array}$} & \multirow{2}{*}{$\begin{array}{l}\mathrm{H}_{\mathrm{O}} \\
0.2444\end{array}$} & \multirow{2}{*}{$\begin{array}{l}\mathrm{H}_{\mathrm{E}} \\
0.4368\end{array}$} & \multirow{2}{*}{$\begin{array}{l}\text { Shannon } \\
\text { Index } \\
0.6285\end{array}$} \\
\hline & & $\begin{array}{l}A \\
G\end{array}$ & $\begin{array}{l}0.6778 \\
0.3222\end{array}$ & $\begin{array}{l}\text { AG } \\
\text { AA } \\
\text { GG }\end{array}$ & $\begin{array}{l}0.2444 \\
0.5556 \\
0.2\end{array}$ & & & \\
\hline c. $535 \mathrm{G}>\mathrm{A}$ & $\mathrm{E} / \mathrm{K}$ & $\begin{array}{l}A \\
G\end{array}$ & $\begin{array}{l}0.3111 \\
0.6889\end{array}$ & $\begin{array}{l}\text { AG } \\
\text { AA } \\
\text { GG }\end{array}$ & $\begin{array}{l}0.3556 \\
0.1333 \\
0.5111\end{array}$ & 0.3556 & 0.4286 & 0.6200 \\
\hline c. $880 \mathrm{G}>\mathrm{A}$ & $\mathrm{V} / \mathrm{L}$ & $\begin{array}{l}\text { A } \\
\text { G }\end{array}$ & $\begin{array}{l}0.3556 \\
0.6444\end{array}$ & $\begin{array}{l}\text { AG } \\
\text { AA } \\
\text { GG }\end{array}$ & $\begin{array}{l}0.4444 \\
0.1333 \\
0.4222 \\
\end{array}$ & 0.4444 & 0.4583 & 0.6508 \\
\hline c. $2308 \mathrm{G}>\mathrm{A}$ & $\mathrm{O} / \mathrm{N}$ & $\begin{array}{l}A \\
G\end{array}$ & $\begin{array}{l}0.7000 \\
0.3000\end{array}$ & $\begin{array}{l}\text { AG } \\
\text { AA } \\
\text { GG }\end{array}$ & $\begin{array}{l}0.2889 \\
0.5556 \\
0.1555\end{array}$ & 0.2889 & 0.4200 & 0.6109 \\
\hline c. $2559 \mathrm{G}>\mathrm{A}$ & G & $\begin{array}{l}A \\
G\end{array}$ & $\begin{array}{l}0.2778 \\
0.7222\end{array}$ & $\begin{array}{l}\text { AG } \\
\text { AA } \\
\text { GG }\end{array}$ & $\begin{array}{l}0.2000 \\
0.1778 \\
0.6222\end{array}$ & 0.2000 & 0.4012 & 0.5908 \\
\hline
\end{tabular}

1 Table 3 Genetic diversity based on SNPs of $N n S B E$ III in the test population. $\mathrm{H}_{\mathrm{O}}$ : the observed heterozygosity; $\mathrm{H}_{\mathrm{E}}$ : the 2 expected heterozygosity 